\title{
RANCANG BANGUN ALAT DETEKSI SUARA PARU-PARU UNTUK MENGANALISA KELAINAN PARU-PARU BERBASIS ANDROID
}

\author{
Dodik Kurniawan, Bingar Sayekti P. \& Eko Agus Suprayitno \\ Universitas Muhammadiyah Sidoarjo \\ e-mail: dodikkurniawan92@gmail.com
}

\begin{abstract}
The plan of lungs' sound detection system with android basis is a development from auscultation technic that supported with signal view in android so that doctor can analyzes the abnormal lungs easily. The plans of instrument are stethoscope as the first detector after that it combines with pre-amp amplifier, low pass filter, high pass filter, notch filter dan output from serial combination structure inter bluetooth to show signal or graph in android smartphone. The trial's value of lungs' sound detection instrument in low pass filter orde 4 frekuensi cutoff $1000 \mathrm{~Hz}$ is the butchering in frequency $900 \mathrm{~Hz}(0,56667 \pm 0,01155)$ is happen, in high pass filter orde 4 frekuensi cutoff $20 \mathrm{~Hz}$, there is butchering in frequency $20 \mathrm{~Hz}$ (0,78667£0,01155). In the patients' lungs' detection, the writer gets information the osiloskop signal is normal by showing sound of lungs when the patient expirates and inspirates. Because the show of lungs' sound in the smartphone android is not clear it needs the high processor specification and program reparation so that it can show the sound of lungs' signal clearly it is like osiloskop.
\end{abstract}

Keywords: Android, Arduino, Bluetooth, Lungs

\begin{abstract}
ABSTRAK
Sistem rancang bangun alat deketsi suara paru-paru berbasis android merupakan pengembangan dari teknik auskultasi yang didukung dengan tampilan sinyal di android untuk mempermudah dokter dalam menganalisa kelainan paru-paru pasien. Perancangan alat terdiri dari stetoskop sebagai pendeteksian awal, kemudian dikuatkan dengan rangkaian pre-amp mic-condenser, low pass filter, high pass filter, notch filter dan output dari ragkaian berkomunikasi serial antar bluetooth untuk menampilkan signal dalam smartphone. Dari hasil pengujian alat deteksi suara paru-paru, untuk rangkaian low pass filter orde 4 frekuensi cutoff $1000 \mathrm{~Hz}$ terjadi pemotongan pada frekuensi $900 \mathrm{~Hz}$ yaitu $(0,56667 \pm 0,01155)$, rangkaian high pass filter orde 4 frekuensi cutoff $20 \mathrm{~Hz}$ terjadi pemotongan pada frekuensi $20 \mathrm{~Hz}$ yaitu $(0,78667 \pm 0,01155)$. Pada pendeteksian kondisi paru-paru pasien memberikan informasi bahwa pada tampilan sinyal diosiloskop tergolong normal, yaitu dengan menampilkan suara paru-paru saat ekspirasi (buang nafas) dan inspirasi (menghirup udara). Untuk tampilan sinyal suara paru-paru dalam smartphone android belum terlihat jelas, perlu spesifikasi prosesor yang tinggi dan perbaikan program sehingga dapat menampilkan sinyal suara paru-paru dengan jelas seperti pada osiloskop.
\end{abstract}

Kata Kunci: Android, Arduino, Bluetooth, Paru-Paru

\section{PENDAHULUAN}

Paru-paru merupakan salah satu organ vital manusia yang memiliki peranan pada sistem pernapasan, karena dapat memenuhi kebutuhan oksigen dalam tubuh. Paru-paru yang mengalami gangguan, akan berdampak pada kinerja sistem pernapasan yang jika tidak ditangani dengan serius dapat menyebabkan kematian. Diperkirakan ratusan ribu sampai jutaan penduduk dunia terkena penyakit paruparu setiap tahun. Berdasarkan proyeksi WHO tahun 2008, penyakit paru-paru masuk dalam 10 besar penyebab masalah kesehatan masyarakat di dunia. Di Indonesia penyakit paru-paru menduduki 10 besar peringkat utama penyebab masalah kesehatan sebagian besar masyarakat Indonesia (Perhimpunan, 2010). Perlunya meningkatkan kepedulian mengenai penyakit paru-paru adalah hal yang vital, 
karena penyakit paru dapat membunuh banyak orang setiap tahunnya dan harus dilakukan segala macam upaya untuk menekan angka kematian penyebab penyakit paru-paru, salah satunya dengan cara mendeteksi secara dini penyakit paru-paru sehingga dapat dilakukan pengobatan dan pencegahan lebih awal. Salah satu contoh penyakit paru-paru adalah Tuberkulosis Paru (TB paru), berdasarkan data Departemen Kesehatan RI (2000), diketahui bahwa TB Paru yang tidak diobati setelah 5 tahun dihasilkan 50\% dari data pasien TB Paru tersebut meninggal, dan $25 \%$ berdampak pada penyakit kronik yang menular serta $25 \%$ pasien sisanya dapat sembuh dengan sendirinya karena tinggginya daya tahan tubuh pasien yang bersangkutan.

Cara yang paling efektif memberantas penyakit TB Paru salah satunya dengan menghentikan TB pada sumbernya yang dikenal dengan strategi DOTS (Direct Observed Treatment Short Course) (WHO, 2003). Namun dalam pelaksanaannya dilapangan, keberhasilan pengobatan dengan strategi DOTS ini mengalami beberapa hambatan antara lain putus berobat dan meninggal sehingga tidak memberikan hasil yang maksimal. Menurut Kemalasari, Wijayanto \& Joko (2011), salah satu metode untuk pendeteksian awal dari penyakit paruparu dapat dilakukan dengan teknik auskultasi menggunakan stetoskop untuk mendengarkan bunyi suara paru-paru. Pengunaan stetoskop sebagai alat bantu diagnosis cenderung sangat subyektif, hasil diagnosis dari dokter sangat tergantung dari kepekaan telinga dan pengalaman jam terbang dari dokter tersebut. Salah satu kelemahan lain yang terjadi, data suara tidak pernah tersimpan sehingga tidak bisa didengarkan bersama-sama dengan dokter lain sebagai bahan pertimbangan dalam memutuskan kondisi penyakit sebenarnya (Achmad Rizal, Suryani, Vera, 2007).

Dalam pembuatan stetoskop akustik yang dipotong bagian earpiece-nya yang kemudian digantikan dengan mic-condenser untuk menangkap suara paru-paru. Kemudian dihubungkan dengan pre-amplifier yang berfungsi untuk menguatkan sinyal masukan sampai 28,2 kali. Untuk penkondisian sinyal High Pass Filter (HPF) dan Low Pass Filter (LPF) akan membentuk Band Pass Filter (BPF) dengan lebar pita 2-2500 Hz. Sinyal kemudian dimasukkan ke PC/Laptop melalui Sound Card sebagai antarmuka. Perangkat yang dibuat didukung oleh perangkat lunak yang mampu merekam, menyimpan dan menampilkan suara paru atau suara jantung yang direkam. dengan hasil tersebut bisa dengan mudah mengklasifikasikan suara jantung dan paru-paru normal dan tidak normal (Budiasih, Rizal \& Sabril, 2011).

Berdasarkan referensi penelitian yang sudah dipaparkan dan pentingnya dalam menganalisa sinyal paru-paru maka pada penelitian ini dibuat "Rancang Bangun Alat Deteksi Suara Paru-paru untuk Menganalisa kelainan Paru-Paru berbasis Android", perancangan alat menggunakan stetoskop sebagai pendeteksi awal suara paru-paru yang dikuatkan dengan rangkaian pre-amplifier untuk penguatan sinyal dari stetoskop, yang dihubungkan dengan rangkaian Low Pass Filter yang memotong sinyal pada frekuensi cutoff $1000 \mathrm{~Hz}$ dan meloloskan sinyal dibawah $1000 \mathrm{~Hz}$, High Pass Filter yang memotong sinyal pada daerah frekuensi $20 \mathrm{~Hz}$ dan meloloskan frekuensi diatas $20 \mathrm{~Hz}$, sedangkan Notch Filter dengan cutoff $50 \mathrm{~Hz}$ untuk mengurangi noise-noise dari jala-jala PLN dan memperhalus tampilan sinyal. Output dari rangkaian tersebut akan dibaca arduino sebagai inputan yang kemudian data hasil pembacaan akan dikomunikasikan secara serial menggunakan bluetooth HC-05 yang selanjutkan akan divisualisasikan dalam smartphone android sehingga bisa membantu dalam menganalisa kelainan paru-paru pasien dan menjadi riwayat pemeriksaan pasien yang lebih efektif dan efisian. Dalam hal ini dokter tidak perlu menganalisa didalam ruangan pemeriksaan, cukup dengan melihat hasil visualisasi yang ditampilkan didalam smartphone android yang bisa dibawa kemana saja. Pasien juga bisa berperan dalam mengetahui hasil signal yang ditampilkan 
sehingga bisa mengetahui riwayat kelainan paru-parunya dan bisa melakukan tindakan pengobatan lebih dini di Rumah Sakit terdekat.

Respiratory sound merupakan bagian dari suara pernafasan paru-paru. Suara pernafasan meliputi suara yang ada pada mulut dan trakea, sedangkan suara pada bagian sekitar dada (chest wall) disebut suara paruparu. Adanya suara di dalam paru-paru manusia disebabkan dari turbulensi udara saat udara masuk ke saluran pernafasan. Perbedaan saluran udara pada sistem pernafasan akan menyebabkan adanya turbulensi sehingga udara mengalir dari saluran yang lebar ke saluran yang lebih sempit begitu juga sebaliknya. Udara yang menabrak dinding saluran pernafasan menyembabkan terjadinya turbulensi sehingga menghasilkan suara. Sedangkan pada saat ekspirasi (buang nafas), udara yang masuk mengalir ke arah berlawanan menuju saluran yang lebih lebar sehingga pada ekspirasi normal terdengar suara lebih kecil dibandingkan pada saat inspirasi (Ramadhan, 2012).

Suara paru-paru dibagi ke dalam tiga kategori, yaitu suara paru-paru normal, suara paru-paru abnormal, dan suara tambahan (adventitious sound). Suara paru-paru tergolong dalam beberapa kategori yang didasarkan pada pitch, intensitas, lokasi, dan rasio antara inspirasi dan ekspirasi. Budiasih, Rizal \& Sabril (2011) menyatakan beberapa jenis suara paru-paru pada Tabel 1.

Tabel 1. Jenis suara paru-paru

\begin{tabular}{cll}
\hline Normal & Abnormal & Adventitious \\
\hline Tracheal & $\begin{array}{l}\text { Absent } \\
\text { /decreased }\end{array}$ & $\begin{array}{l}\text { crackles } \\
\text { (rales) }\end{array}$ \\
Vesicular & $\begin{array}{l}\text { Harsh } \\
\text { Vesicular }\end{array}$ & Wheeze \\
Bronchial & & Rhonchi \\
Broncho- & & Stridor \\
vesicular & & pleural rub \\
& & \\
\hline
\end{tabular}

Teknik yang sering digunakan untuk mendeteksi suara paru-paru yaitu teknik auskultasi. Auskultasi harus dilakukan di seluruh permukaan dada dan punggung. Teknik auskultasi dimulai dari atas ke bawah, kemudian dibandingkan sisi kiri dan kanan dada. (Matondang, Wahidayat \& Sastroasmono, 2003). Menurut Yunisya (2014), banyak Masalah yang timbul saat menggunakan teknik auskultasi yaitu frekuensi suara dari dalam tubuh relatif rendah sekitar 20-400 Hz, amplitudo rendah, kepekaan telinga dan kebisingan lingkungan. Apabila prosedur auskultasi tidak dilakukan dengan benar dapat menyebabkan kesalahan menentukan hasil diagnosa pasien. Gambar 1 merupakan posisi auskultasi suara paru-paru yang selalu di lakukan oleh dokter spesialis paru.
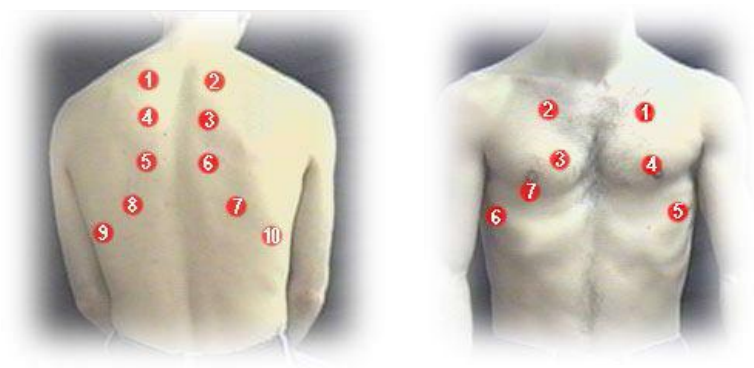

Gambar 1. Posisi auskultasi suara paru-paru

(Budiasih, Rizal \& Sabril, 2011)

Arduino (electronic board) adalah papan rangkaian elektronik open source yang memiliki komponen utama di dalamnya yaitu sebuah chip mikrokontroller. Mikrokontroller ATMega328 yang dirancang untuk bisa digunakan dengan mudah oleh desainer (yang memang bukan orang teknik). Arduino merupakan salah satu platform yang mempunyai input hardware open sourcel output (I/O) yang sederhana. Board arduino uno mempunyai 6 input analog, 14 input digital I/O, 6 PWM output dengan menggunakan baterai / power supply 6-20 volt DC. Gambar 2 merupakan bentuk dari arduino uno yang biasa ada dipasaran.

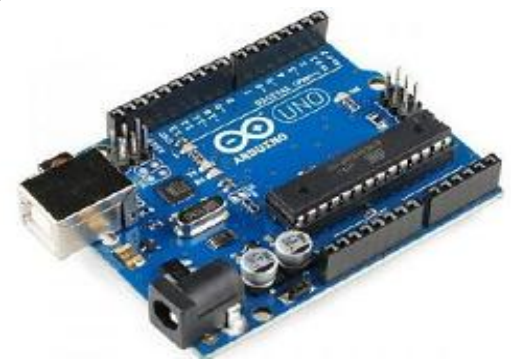

Gambar 2. Arduino uno (Dian, 2012) 
Bluetooth adalah protokol komunikasi wireless yang bekerja pada frekuensi radio 2.4 $\mathrm{GHz}$ yang berfungsi untuk pertukaran data pada perangkat bergerak seperti laptop, HP, dan lain-lain. Bluetooth tipe HC-05 adalah Salah satu hasil contoh modul Bluetooth yang paling sering digunakan dan banyak ditemukan dipasaran dengan harga yang relatif murah. Modul Bluetooth HC-05 terdiri dari 6 pin konektor, setiap pin konektor memiliki fungsi yang berbeda - beda. Modul Bluetooth mempunyai dua model yaitu master device dan slave device. Untuk modul bluetooth HC-05 seperti pada Gambar 3 bisa menjadi master atau slave karena modul ini bisa memberikan notifikasi untuk melakukan pairing keperangkat lain, ataupun perangkat lain melakukan pairing dengan bluetooth HC-05.

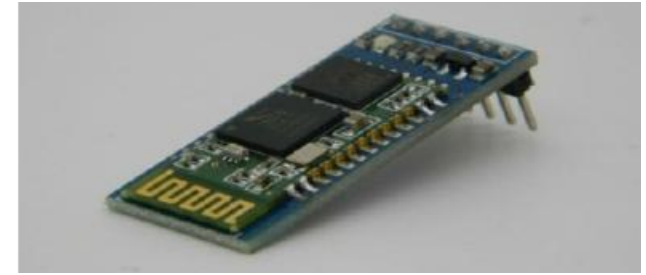

Gambar 3 . Modul Bluetooth HC-05 (Oky, Hari, \& Sungkono, 2014)

Rangkaian pre-amplifier berfungsi untuk menguatkan sinyal, karena suara paru-paru berada pada frekuensi rendah. Maka suara yang ditangkap stetoskop mic-condenser dikuatkan dengan rangkaian pre-amplifier agar frekuensi sinyal suara paru-paru menjadi besar, Gambar 4 merupakan skematik rangkaian pre-amp mic condenser.

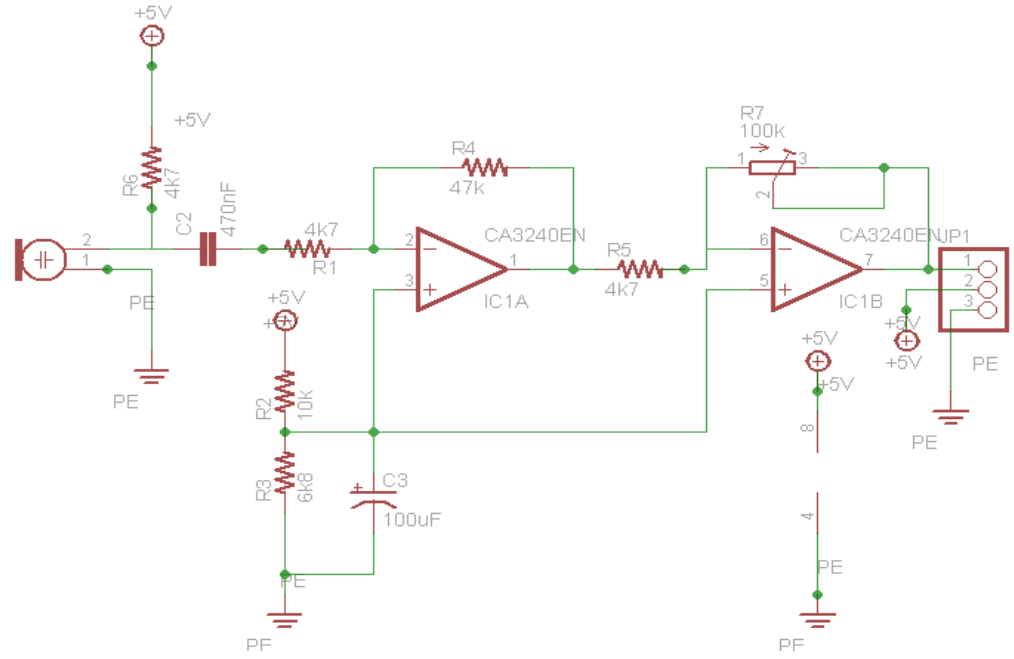

Gambar 4. Rangkaian Pre-Amp Mic Condenser

Rangkaian low pass filter frekuensi cutoff $1000 \mathrm{~Hz}$ berfungsi meloloskan sinyal pada frekuensi dibawah $1000 \mathrm{~Hz}$ dan memotong sinyal atau memperkecil sinyal pada frekuensi diatas $1000 \mathrm{~Hz}$. Rangkaian low pass filter orde 4 dibentuk dari 2 buah rangkaian low pass filter orde 2 Sallen-Key Topology seperti diagram blok Gambar. 5 dan rangkaian skematik pada Gambar. 6. Nilai koefisien Butterworth untuk orde 4 yaitu $a_{1}=1.8478 ; b_{1}$ $=1.0000 ; \mathrm{a}_{2}=0.7654$ dan $\mathrm{b}_{2}=1.0000$. Low Pass Filter orde 2 pertama dan kedua dapat dihitung dengan persamaan (1) dan (2) dengan nilai $\mathrm{C}_{1}=47 \mathrm{nF}$. Untuk rangkaian orde 2 kedua dengan mengganti nilai $\mathrm{R}_{1}$ menjadi $\mathrm{R}_{3} ; \mathrm{R}_{2}$ menjadi $\mathrm{R}_{4} ; \mathrm{C}_{1}$ menjadi $\mathrm{C}_{3} ; \mathrm{C}_{2}$ menjadi $\mathrm{C}_{4} ; \mathrm{a}_{1}$ menjadi $a_{2} ; b_{1}$ menjadi $b_{2}$.

$$
\begin{gathered}
C_{2} \geq C_{1} \frac{4 b_{1}}{a_{1}^{2}} \ldots . .(1) \\
R_{1,2}=\frac{a_{1} \cdot C_{2} \pm \sqrt{a_{1}^{2}+C_{2}^{2}-4 \cdot b_{1} \cdot C_{1} \cdot C_{2}}}{4 \pi \cdot f c \cdot C_{1} \cdot C_{2}} \ldots . .
\end{gathered}
$$

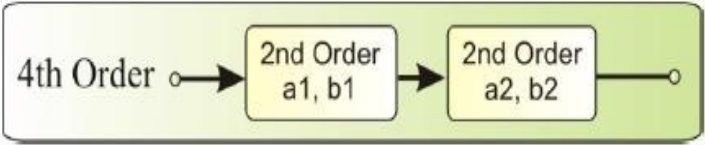

Gambar. 5 Susunan tahapan low pass filter Orde 4 (Suprayitno \& Arifin, 2012) 


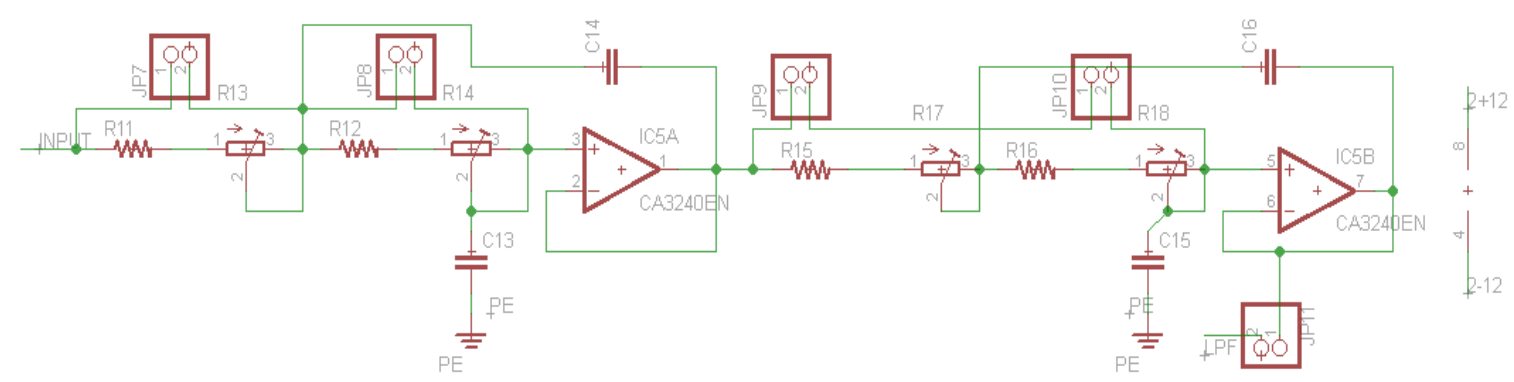

Gambar. 6 Rangkain low pass filter orde 4 frekuensi cut off $1000 \mathrm{~Hz}$

Rangkaian high pass filter frekuensi 20 $\mathrm{Hz}$ berfungsi meloloskan sinyal pada frekuensi diatas $20 \mathrm{~Hz}$ dan memotong sinyal pada frekuensi dibawah $20 \mathrm{~Hz}$. Rangkaian high pass filter orde 4 yaitu penggabungan dari 2 buah rangkaian orde 2 Sallen-Key Topology seperti diagram blok pada Gambar. 5 dan rangkaian skematik pada Gambar. 7. Nilai $a_{1}=1.8478 ; b_{1}$ $=1.0000 ; \mathrm{a}_{2}=0.7654$ dan $\mathrm{b}_{2}=1.0000$ merupakan koefisien Butterworth untuk orde 4.
Dengan menggunakan nilai $\mathrm{C}_{1}=\mathrm{C}_{2}=1 \mu \mathrm{F}, \mathrm{a}_{1}=$ 1.8478 dan $b_{1}=1.0000$ untuk frekuensi cutoff $20 \mathrm{~Hz}$ nilai $\mathrm{R}_{1}, \mathrm{R}_{2}$ dapat dihitung dengan persamaan (3) dan (4) berikut.

$$
\begin{aligned}
R_{1} & =\frac{1}{\pi \cdot f c \cdot C \cdot a_{1}} \cdots \\
R_{2} & =\frac{a_{1}}{4 \cdot \pi \cdot f c \cdot C \cdot b_{1}}
\end{aligned}
$$

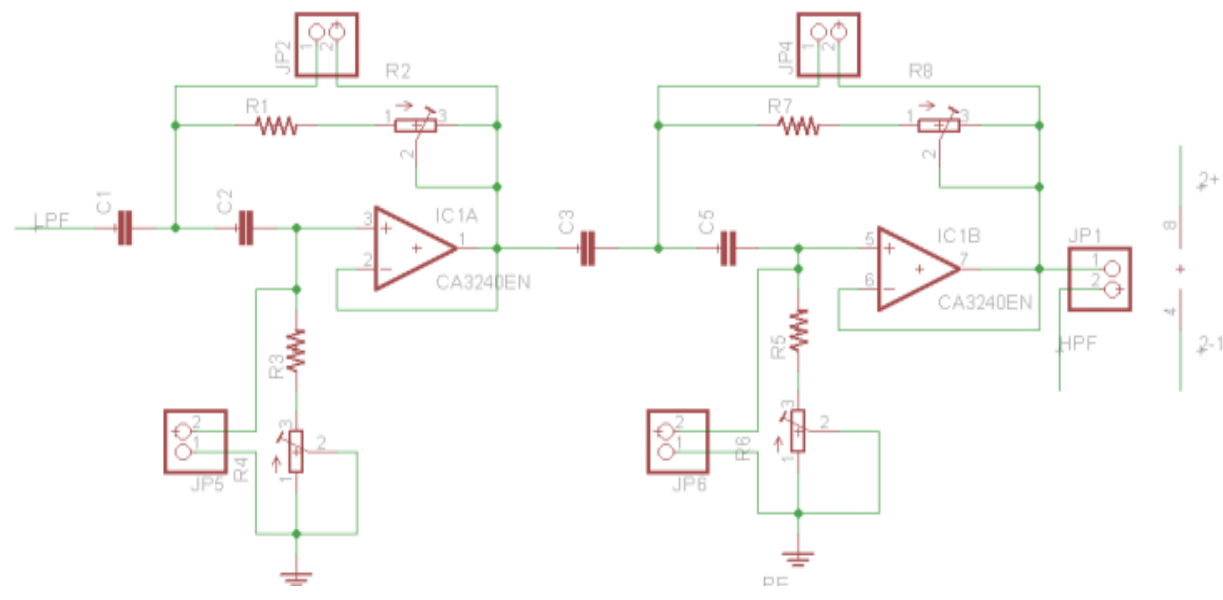

Gambar. 7 Rangkain high pass filter orde 4 frekuensi cut off $20 \mathrm{~Hz}$

Rangkaian notch filter digunakan untuk menghilangkan noise jala-jala frekuensi $50 \mathrm{~Hz}$ pada generator tegangan maupun yang ditimbulkan asiloskop. Gambar 8 merupakan rangkaian notch filter frekuensi cut off $50 \mathrm{~Hz}$. Nilai $\mathrm{C}_{1}$ yang digunakan sebesar $1 \mu \mathrm{F}, \mathrm{RA}=$ $1 \mathrm{k} \Omega$. Nilai Center frekuensi $\omega \mathrm{r}$, nilai Quality Factor $(\mathrm{Q}), \mathrm{R}_{2}, \mathrm{R}_{1}$, dan $\mathrm{RB}$ dihitung dengan persamaan (5),(6),(7),(8) dan (9).

$$
\begin{gathered}
\omega_{r}=2 . \pi \cdot f c \ldots . . \\
Q=\frac{\omega_{r}}{B} \ldots . . \\
R_{2}=\frac{2}{B C} \ldots . . \\
R_{1}=\frac{R_{2}}{4 \cdot Q^{2}} \ldots . \\
R B=2 \cdot Q^{2} \cdot R_{a} \ldots
\end{gathered}
$$




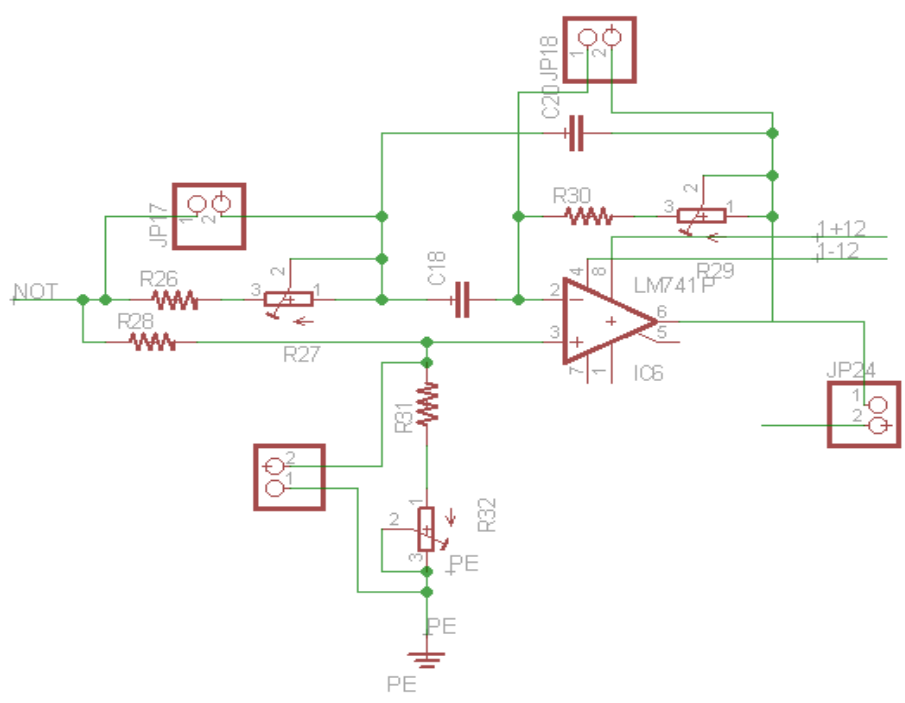

Gambar. 8 Rangkain notch filter

Rangkain clamper digunakan untuk bisa ditampilkan keseluruhan sinyal pada menaikkan posisi sinyal suara paru-paru berada pada level tegangan positif agar sinyal dapat tampilan android. Berikut skema rangkaian terbaca oleh ADC pada arduino uno. Sehingga clamper seperti Gambar 9.

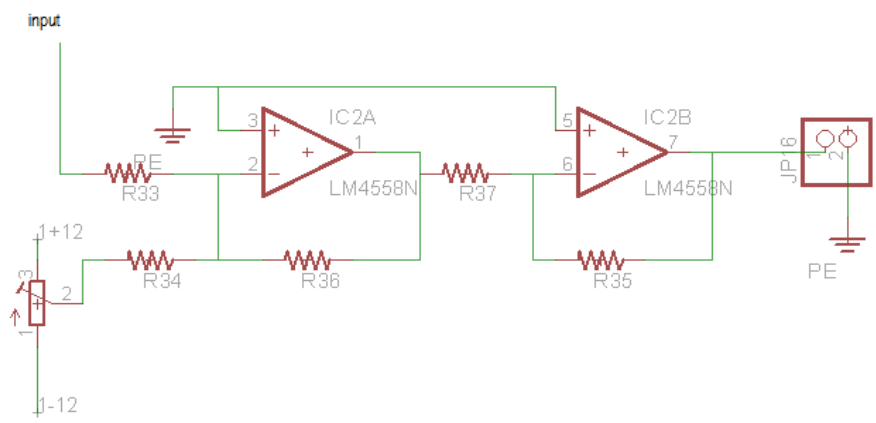

Gambar. 9 Rangkain clamper

\section{METODE}

Saat ini teknik diagnosa kondisi suara paru-paru manusia umumnya menggunakan stetoskop untuk mendengarkan suara paru-paru pada pasien. Maka untuk memudahkan diagnosa kondisi paru-paru yaitu dengan melihat hasil data sinyal suara paru-paru. Dengan memanfaatkan alat elektronik maka dapat menampilkan sinyal suara paru-paru di osiloskop dan smartphone. Dengan arduino yang mempunyai pin I/O maka dapat membaca nilai ADC suara paru-paru yang dikirim oleh rangkaian dan disertai komunikasi serial antar bluetooh sehingga bisa memvisualisasikan sinyal suara paru-paru.
Secara umum, pengembangan Alat Deteksi Suara Paru-paru berbasis Android dilakukan beberapa tahapan, yaitu analisis, desain, pengembangan dan pengujian. Penelitian dilakukan dimulai dari analisis, yaitu menganalisis karakteristik data suara paru-paru dan mengidentifikasi kebutuhan rangkaian pada Alat Deteksi Suara Paru-paru berbasis Android. Pengembangan dilakukan berdasarkan hasil desain yang dirancang dengan memperhatikan hasil analisis. Pengujian merupakan tahapan yang digunakan untuk menilai keberfungsian alat yang dikembangkan. Data suara paru-paru diambil di Jl. Raya Gelam No.250 Laboratorium Teknik Elektro Universitas Sidoarjo. 
Hasil analisis menunjukkan bahwa input sinyal suara paru-paru memiliki karakteristik suara yang sangat rendah. Identifikasi kebutuhan rangkaian yang diperoleh dari karakteristik sinyal tersebut maka dibutuhkan beberapa rangkaian, yaitu: (1) Input berupa besaran nilai adc yang berasal dari suara paruparu manusia; (2) proses terdiri dari: (a) pengkondisi sinyal berupa: (i) pre-amp untuk menguatkan sinyal; (ii) low pass filter untuk meloloskan sinyal pada frekuensi dibawah $1000 \mathrm{~Hz}$ dan memotong sinyal atau memperkecil sinyal pada frekuensi diatas 1000 $\mathrm{Hz}$; (iii) high pass filter untuk meloloskan sinyal pada frekuensi diatas $20 \mathrm{~Hz}$ dan memotong sinyal pada frekuensi dibawah 20 $\mathrm{Hz}$; (iv) notch filter untuk menghilangkan noise-noise hasil keluaran tegangan yang dihasilkan legulator dan listrik frekuensi $50 \mathrm{~Hz}$, agar sinyal suara paru-paru yang ditampilkan lebih bagus dan halus; dan (v) clamper untuk menaikkan posisi sinyal suara paru-paru berada pada level tegangan positif agar sinyal dapat terbaca oleh ADC pada arduino uno; (b) kontroler untuk memproses data yang diterima dari rangkaian untuk dikirimkan ke handphone android, dalam hal ini dipilih arduino uno karena proses pengkodingan sangat mudah dan simple; dan (c) bluetooth untuk berkomunikasi serial dengan arduino dan mengirim data sinyal suara paru-paru; serta (3) output berupa tampilan sinyal suara paru-paru pada handphone android. Handphone memiliki spesifikasi minimal dengan RAM 1 Gb untuk memperlancar tampilan sinyal pada layar handphone.

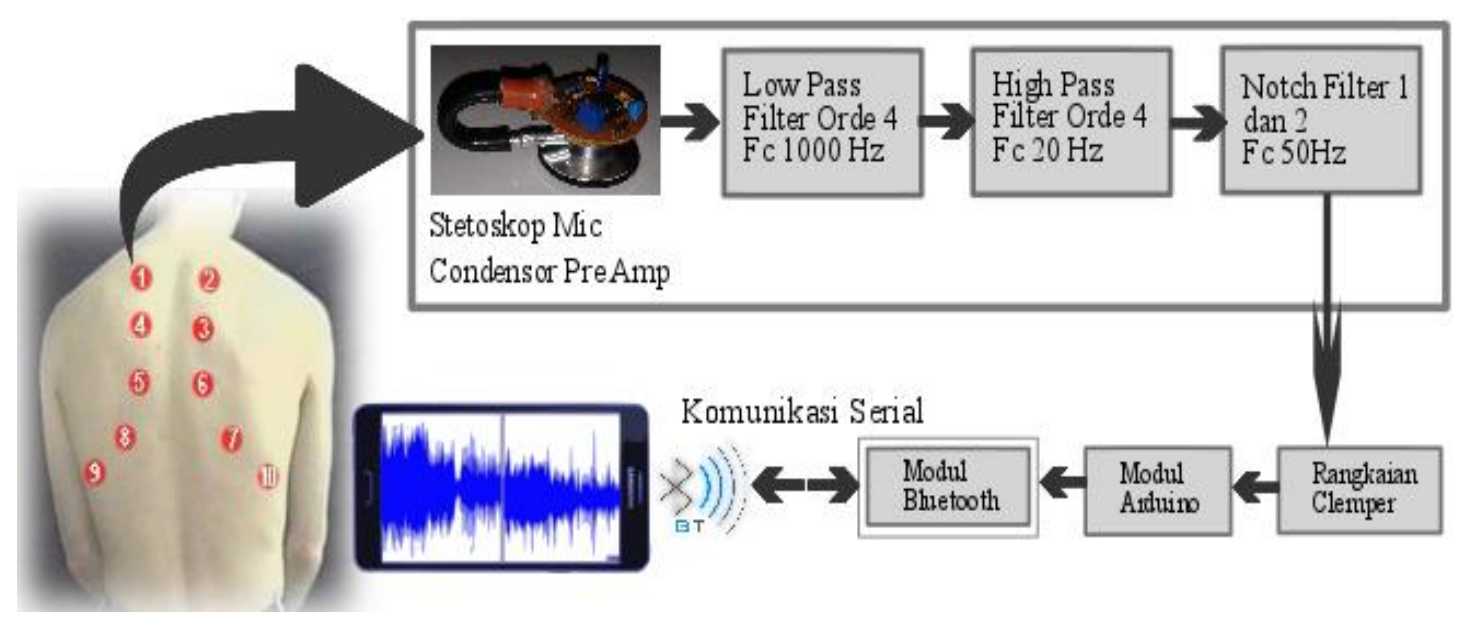

Gambar 10. Blok diagram

Gambaran secara umum mengenai alat yang dikembangkan dapat ditunjukkan pada Gambar 10. Blok diagram tersebut meliputi: (1) Paru - paru manusia sebagai input data sinyal suara paru-paru; (2) Stetoskop mic condensor pre-amp untuk pendeteksian sinyal suara paru-paru; (3) Low Pass Filter orde 4 frekuensi CutOff $1000 \mathrm{~Hz}$ sebagai filter yang meloloskan sinyal pada frekuensi dibawah $1000 \mathrm{~Hz}$ dan memotong sinyal atau memperkecil sinyal pada frekuensi diatas 1000 $\mathrm{Hz}$; (4) High Pass Filter orde 4 frekuensi CutOff $20 \mathrm{~Hz}$ sebagai filter yang meloloskan sinyal pada frekuensi diatas $20 \mathrm{~Hz}$ dan memotong sinyal pada frekuensi dibawah 20
$\mathrm{Hz}$; (5) Notch Filter frekuensi $50 \mathrm{~Hz}$ untuk menghilangkan noise-noise hasil keluaran tegangan yang dihasilkan legulator dan listrik frekuensi $50 \mathrm{~Hz}$, agar sinyal suara paru-paru yang ditampilkan lebih bagus dan halus; (6) Rangkaian clamper digunakan untuk menaikkan tegangan pada sinyal suara paruparu; (7) Arduino uno digunakan untuk membaca data adc suara paru-paru dan mengirim data sinyal suara paru-paru dengan komunikasi serial dengan mobile android; (8) Modul Bluetooth berkomunikasi serial dengan arduino dan mengirim data sinyal suara paru pada bluetooth yang ada pada handphone android; dan (9) Handphone berbasis android 
menampilkan data sinyal suara paru yang telah diterima dari komunikasi bluetooth, tampilan sinyal suara paru dengan bantuan software eclipse.

Hasil desain dapat ditunjukkan pada skema rangkaian keseluruhan yang disajikan pada Gambar 11. Gambar menunjukkan skema rangkaian keseluruhan yang terdiri dari rangkaian pre-amp mic condenser, rangkaian low pass fiter, rangkaian high pass filter, rangkaian notch filter, rangkaian clamper, arduino, dan bluetooth.

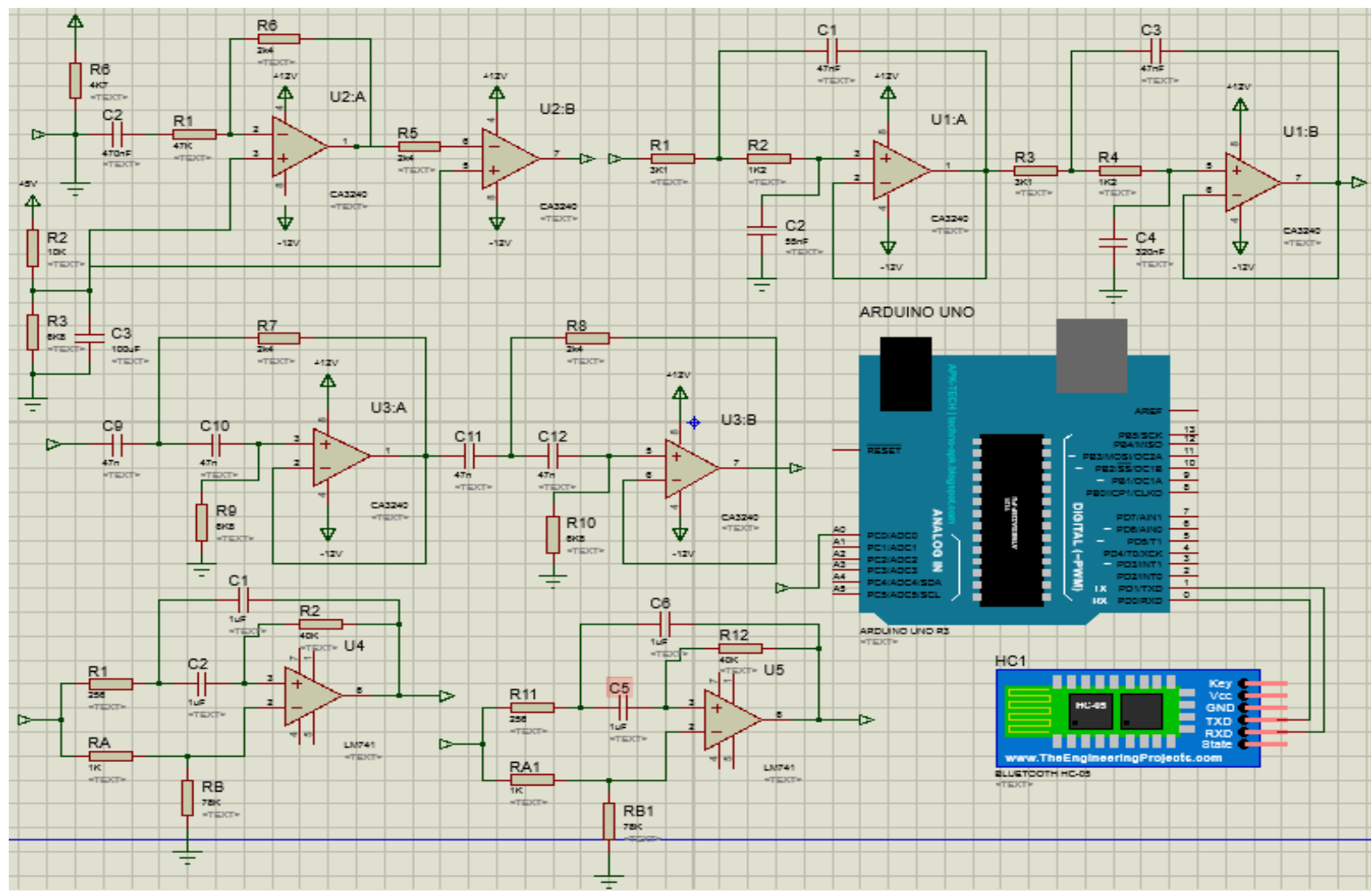

Gambar. 11 Skema rangkaian keseluruhan

HASIL

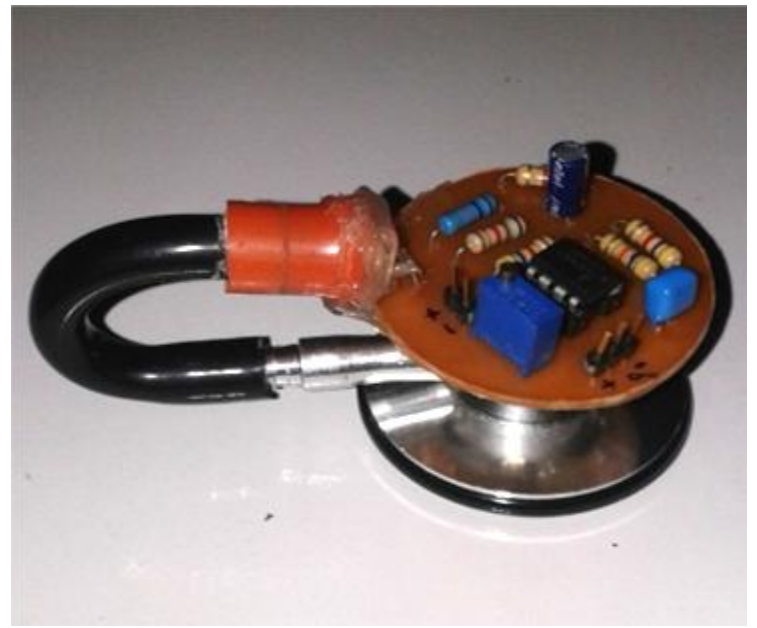

Gambar. 12 Stetoskop Mic Condenser
Hasil Pengujian dan analisa dilakukan untuk mengetahui apakah alat yang telah dibuat dapat berfungsi sesuai yang diharapkan. Gambar 12 menunjukan stetoskop mic condenser. Pengujian stetoskop mic-condenser yaitu untuk mengetahui apakah rangkaian stetoskop mic-condenser dapat mendeteksi atau menangkap sinyal suara paru-paru manusia. Posisi pengambilan sinyal suara paru-paru diambil pada posisi trakea dimana merupakan jalur percabangan antara paru-paru kanan dan kiri. Dari hasil yang didapat dengan melihat Gambar 13 maka rangkaian stetoskop mic condenser sudah dapat mendeteksi suara paruparu manusia, walaupun masih banyak noisenoise yang ditimbulkan dan sinyalnya masih tercampur dengan sinyal jantung manusia. 


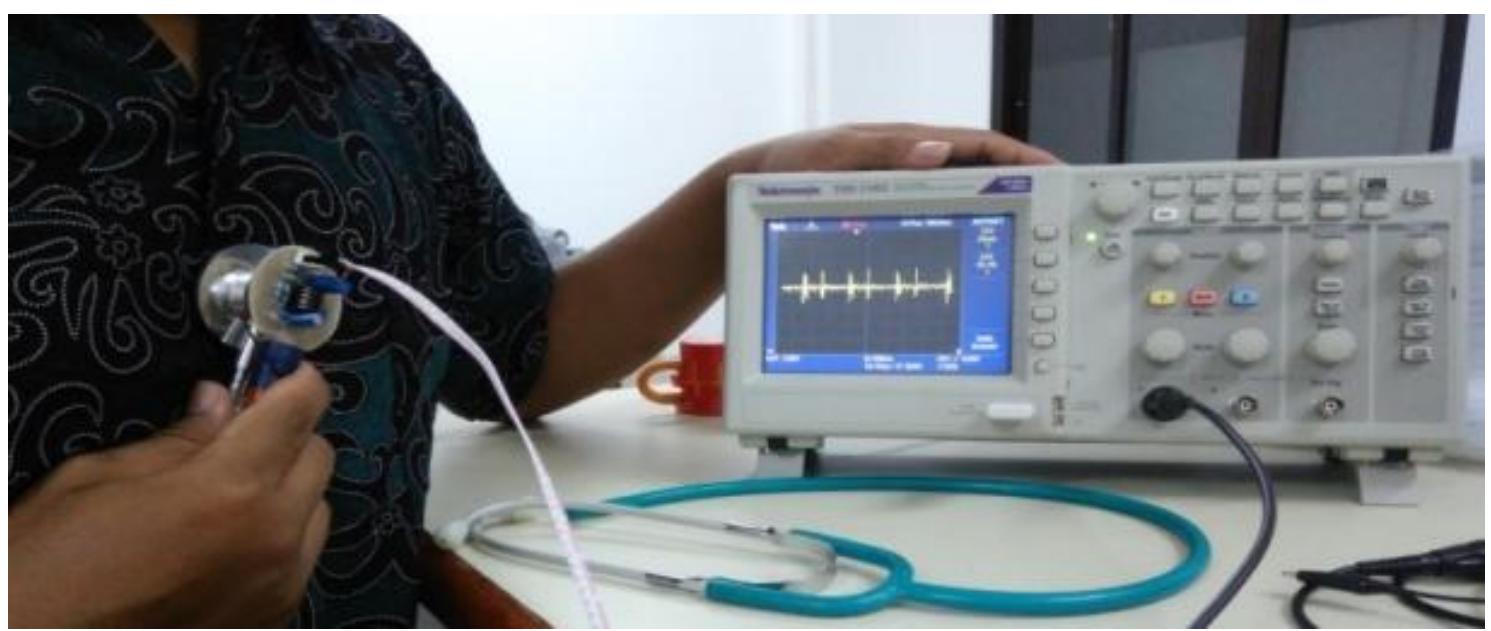

Gambar. 13 Hasil Pengujian Stetoskop Mic Condenser

Dari hasil pengujian akurasi rangkaian low pass filter orde 4 frekuensi cutoff $1000 \mathrm{~Hz}$, bisa dilihat dari Tabel 2 hasil pengujian dengan setting tegangan output function generator 1 volt dan frekuensi input $50 \mathrm{~Hz}$ sampai $1500 \mathrm{~Hz}$ dilakukan dengan 3 kali percobaan inputan frekuensi yang sama dari generator sehingga dihasilkan grafik seperti pada Gambar 14. Dilihat dari hasil grafik dengan 3 kali pengujian hasil yang didapat tidak jauh beda, grafik yang dihasilkan hampir sama dan terjadi pemotongan atau pengecilan sinyal pada frekuensi $900 \mathrm{~Hz}$ yaitu $(0,56667 \pm 0,01155)$, dengan demikian rangkain low pass filter sudah mampu meloloskan frekuensi $0 \mathrm{~Hz}$ dan mengecilkan frekuensi diatas $1000 \mathrm{~Hz}$.

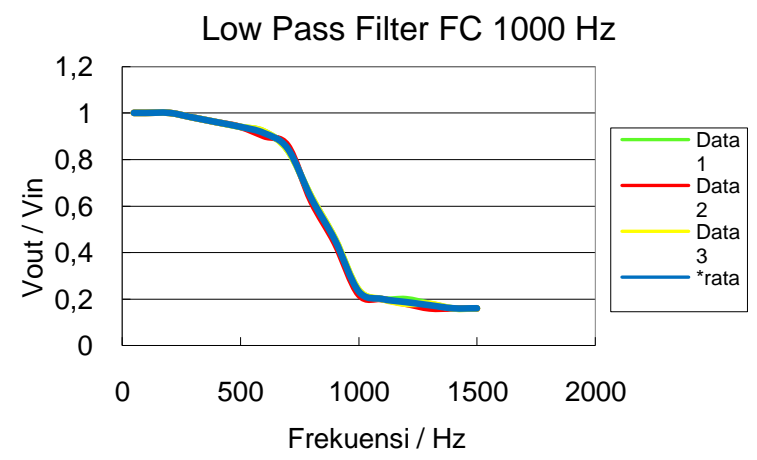

Gambar. 14 Grafik Hasil Pengujian Rangkaian Low Pass Filter Orde 4 Frekuensi Cutoff $1000 \mathrm{~Hz}$

Tabel 2. Hasil uji rangkaian low pass filter orde 4 frekuensi cutoff $1000 \mathrm{~Hz}$

\begin{tabular}{rccccrr}
\hline \multirow{2}{*}{ No } & Vin(Pk-Pk)=1Volt & \multicolumn{3}{c}{ V out Percobaan Ke- } & \multicolumn{2}{c}{ Hasil Analisa } \\
& Frekuensi Hz & Data1 & Data 2 & Data 3 & *rata & *set dev \\
\hline 1 & 50 & 1 & 1 & 1 & 1 & 0 \\
2 & 100 & 1 & 1 & 1 & 1 & 0 \\
3 & 200 & 1 & 1 & 1 & 1 & 0 \\
4 & 300 & 0.98 & 0.98 & 0.98 & 0.98 & 0 \\
5 & 400 & 0.96 & 0.96 & 0.96 & 0.96 & 0 \\
6 & 500 & 0.94 & 0.94 & 0.94 & 0.94 & 0 \\
7 & 600 & 0.92 & 0.9 & 0.92 & 0.913 & 0.011 \\
8 & 700 & 0.9 & 0.9 & 0.9 & 0.90 & 0 \\
9 & 800 & 0.84 & 0.84 & 0.84 & 0.84 & 0 \\
10 & 900 & 0.58 & 0.56 & 0.56 & 0.566 & 0.011 \\
11 & 1000 & 0.24 & 0.22 & 0.24 & 0.233 & 0.011 \\
12 & 1100 & 0.20 & 0.20 & 0.20 & 0.2 & 0 \\
13 & 1200 & 0.20 & 0.18 & 0.18 & 0.186 & 0.011 \\
14 & 1300 & 0.18 & 0.16 & 0.18 & 0.173 & 0.011 \\
15 & 1400 & 0.16 & 0.16 & 0.16 & 0.16 & 0 \\
16 & 1500 & 0.16 & 0.16 & 0.16 & 0.16 & 0 \\
\hline
\end{tabular}


Tabel 3 merupakan hasil pengujian rangkaian high pass filter orde 4 frekuensi cuttoff $20 \mathrm{~Hz}$ dengan pengujian sebanyak 3 kali, setting inputan function generator output 1 volt, dan nilai sinyal frekuensi $10 \mathrm{~Hz}$ sampai $150 \mathrm{~Hz}$ sehingga dihasilkan grafik seperti pada Gambar. 15. Dilihat dari hasil grafik dengan 3 kali pengujian hasil yang didapat tidak jauh beda, grafik yang dihasilkan hampir sama dan terjadi pemotongan atau pengecilan sinyal pada frekuensi $20 \mathrm{~Hz}$ yaitu $(0,78667 \pm 0,01155)$, dengan demikian rangkain high pass filter sudah mampu meloloskan frekuensi diatas 20 $\mathrm{Hz}$ dan mengecilkan frekuensi dibawah $20 \mathrm{~Hz}$.
High Pass Filter FC $20 \mathrm{~Hz}$

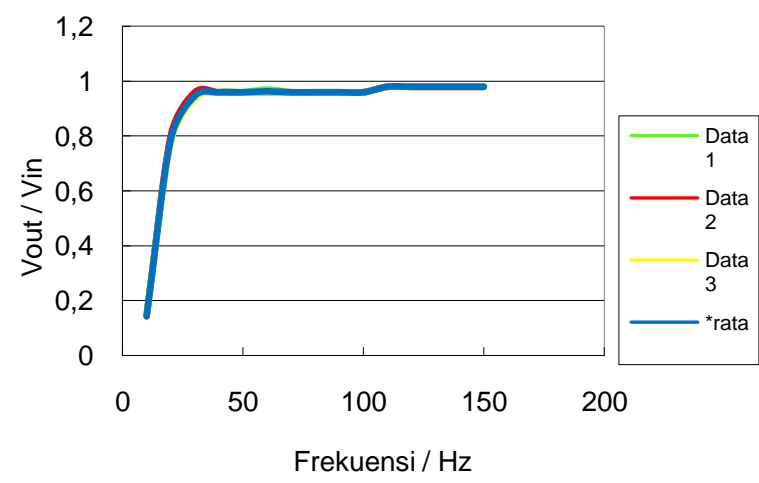

Gambar. 15 Grafik Hasil Pengujian Rangkaian high Pass Filter Orde 4 Frekuensi Cutoff $20 \mathrm{~Hz}$

Tabel 3. Hasil uji rangkaian high pass filter orde 4 frekuensi cutoff $20 \mathrm{~Hz}$

\begin{tabular}{rccccrr}
\hline \multirow{2}{*}{ No } & Vin(Pk-Pk)=1 Volt & \multicolumn{3}{c}{ V out Percobaan Ke- } & \multicolumn{2}{c}{ Hasil Analisa } \\
& Frekuensi Hz & Data1 & Data2 & Data3 & *rata & *set dev \\
\hline 1 & 10 & 0.14 & 0.14 & 0.15 & 0.145 & 0.001 \\
2 & 20 & 0.78 & 0.8 & 0.78 & 0.786 & 0.011 \\
3 & 30 & 0.94 & 0.96 & 0.94 & 0.946 & 0.011 \\
4 & 40 & 0.96 & 0.96 & 0.96 & 0.96 & 0 \\
5 & 50 & 0.96 & 0.96 & 0.96 & 0.96 & 0 \\
6 & 60 & 0.97 & 0.96 & 0.96 & 0.963 & 0.005 \\
7 & 70 & 0.96 & 0.96 & 0.96 & 0.96 & 0 \\
8 & 80 & 0.96 & 0.96 & 0.96 & 0.96 & 0 \\
9 & 90 & 0.96 & 0.96 & 0.96 & 0.96 & 0 \\
10 & 100 & 0.96 & 0.96 & 0.96 & 0.96 & 0 \\
11 & 110 & 0.98 & 0.98 & 0.98 & 0.98 & 0 \\
12 & 120 & 0.98 & 0.98 & 0.98 & 0.98 & 0 \\
13 & 130 & 0.98 & 0.98 & 0.98 & 0.98 & 0 \\
14 & 140 & 0.98 & 0.98 & 0.98 & 0.98 & 0 \\
15 & 150 & 0.98 & 0.98 & 0.98 & 0.98 & 0 \\
\hline
\end{tabular}

Pengujian rangkaian seri notch filter 1 dan 2 dilakukan untuk mengetahui terjadinya pengecilan atau pemotongan pada frekuensi 50 $\mathrm{Hz}$, pengujian ini dilakukan agar noise dari jala-jala PLN dengan frekuensi $50 \mathrm{~Hz}$ semakin kecil atau semakin tajam pemotongannya. Pada tabel 4 dibawah ini merupakan hasil pengujian rangkaian seri notch filter 1 dan 2 frekuensi cutoff $50 \mathrm{~Hz}$ dengan pengujian sebanyak 3 kali, setting inputan function generator output tegangan 1 volt, dan nilai sinyal frekuensi 10 $\mathrm{Hz}$ sampai $150 \mathrm{~Hz}$, terjadi pemotongan lebih tajam yaitu $(0.22667 \pm 0.011547)$ seperti yang ditunjukkan pada Gambar 16.

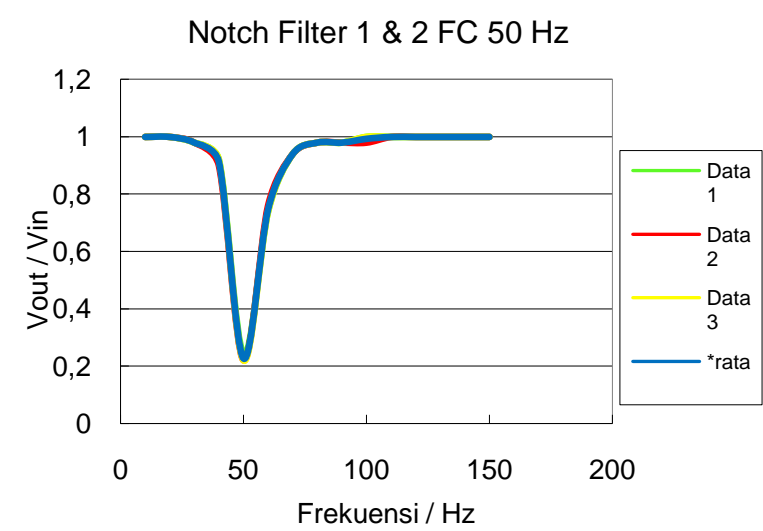

Gambar. 16 Grafik Hasil Pengujian Rangkaian Seri Notch Filter 1 dan 2 Frekuensi Cutoff $50 \mathrm{~Hz}$ 
Tabel 4. Hasil uji rangkaian seri notch filter 1 dan 2 frekuensi cutoff $50 \mathrm{~Hz}$

\begin{tabular}{rccccrrr}
\hline \multirow{2}{*}{ No } & $\begin{array}{c}\text { Vin(Pk-Pk)=1Volt } \\
\text { Frekuensi Hz }\end{array}$ & \multicolumn{3}{c}{ Vout Percobaan Ke- } & \multicolumn{2}{c}{ Hasil Analisa } \\
& 10 & 1 & Data2 & Data3 & *ata & *set dev \\
\hline 1 & 20 & 1 & 1 & 1 & 1 & 0 \\
2 & 30 & 0.98 & 0.98 & 0.98 & 1 & 0 \\
3 & 40 & 0.92 & 0.9 & 0.92 & 0.913 & 0.011 \\
4 & 50 & 0.24 & 0.22 & 0.22 & 0.226 & 0.011 \\
5 & 60 & 0.74 & 0.76 & 0.74 & 0.746 & 0.011 \\
6 & 70 & 0.94 & 0.94 & 0.94 & 0.94 & 0 \\
7 & 80 & 0.98 & 0.98 & 0.98 & 0.98 & 0 \\
8 & 90 & 0.98 & 0.98 & 0.98 & 0.98 & 0 \\
9 & 100 & 1 & 0.98 & 1 & 0.993 & 0.011 \\
10 & 110 & 1 & 1 & 1 & 1 & 0 \\
11 & 120 & 1 & 1 & 1 & 1 & 0 \\
12 & 130 & 1 & 1 & 1 & 1 & 0 \\
13 & 140 & 1 & 1 & 1 & 1 & 0 \\
14 & 150 & 1 & 1 & 1 & 1 & 0 \\
15 & & & & & & 1 \\
\hline
\end{tabular}

Pengujian Bluetooth HC-05 dilakukan untuk mengetahui seberapa jauh jarak koneksi bluetooth HC-05 dengan bluetooth smartphone. Pengujian dilakukan dengan penghalang dengan cara meletakkan alat dan bluetooth HC-05 didalam ruangan kemudian melukakn proses koneksi dengan bluetooth smartphone yang berada diluar ruangan. Hasil pengujian diperoleh data seperti pada Tabel 5 yaitu proses pairing dan Tabel 6 proses pengiriman data. Jangkauan koneksi bluetooth pada saat proses pairing memiliki jangkauan yang lebih dekat dari pada proses pengiriman data. Pada proses pairing jarak maksimal tanpa halangan 7 meter, dengan halangan dinding beton 2 meter, dan dengan halangan dinding triplek 4 meter, sedangkan pada proses pengiriman data diperoleh jarak tanpa halangan 13 meter, dengan halangan dinding beton 5 meter, dan dengan halangan dinding triplek 9 meter.
Tabel 5. Hasil uji jangkauan bluetooth pada saat proses pairing

\begin{tabular}{ccccc}
\hline & & \multicolumn{3}{c}{ Proses Pairing } \\
No & $\begin{array}{c}\text { Darak } \\
(\mathrm{m})\end{array}$ & $\begin{array}{c}\text { Tanpa } \\
\text { Penghalang }\end{array}$ & $\begin{array}{c}\text { Dinding } \\
\text { Beton }\end{array}$ & $\begin{array}{c}\text { Dinding } \\
\text { Triplek }\end{array}$ \\
\hline 1 & 1 & Berhasil & Berhasil & Berhasil \\
2 & 2 & Berhasil & Berhasil & Berhasil \\
3 & 3 & Berhasil & Gagal & Berhasil \\
4 & 4 & Berhasil & Gagal & Berhasil \\
5 & 5 & Berhasil & Gagal & Gagal \\
6 & 6 & Berhasil & Gagal & Gagal \\
7 & 7 & Berhasil & Gagal & Gagal \\
8 & 8 & Gagal & Gagal & Gagal \\
9 & 9 & Gagal & Gagal & Gagal \\
10 & 10 & Gagal & Gagal & Gagal \\
11 & 11 & Gagal & Gagal & Gagal \\
12 & 12 & Gagal & Gagal & Gagal \\
13 & 13 & Gagal & Gagal & Gagal \\
14 & 14 & Gagal & Gagal & Gagal \\
15 & 15 & Gagal & Gagal & Gagal \\
\hline
\end{tabular}


Tabel 6. Hasil uji jangkauan bluetooth pada saat proses pengiriman data

\begin{tabular}{ccccc}
\hline & & \multicolumn{3}{c}{ Proses Pengiriman Data } \\
No & $\begin{array}{c}\text { Jarak } \\
(\mathrm{m})\end{array}$ & $\begin{array}{c}\text { Tanpa } \\
\text { Penghalang }\end{array}$ & $\begin{array}{c}\text { Dengan Penghalang } \\
\text { Dinding } \\
\text { Beton }\end{array}$ & $\begin{array}{c}\text { Dinding } \\
\text { Triplek }\end{array}$ \\
\hline 1 & 1 & Berhasil & Berhasil & Berhasil \\
2 & 2 & Berhasil & Berhasil & Berhasil \\
3 & 3 & Berhasil & Berhasil & Berhasil \\
4 & 4 & Berhasil & Berhasil & Berhasil \\
5 & 5 & Berhasil & Berhasil & Berhasil \\
6 & 6 & Berhasil & Terputus & Berhasil \\
7 & 7 & Berhasil & Terputus & Berhasil \\
8 & 8 & Berhasil & Terputus & Berhasil \\
9 & 9 & Berhasil & Terputus & Berhasil \\
10 & 10 & Berhasil & Terputus & Terputus \\
11 & 11 & Berhasil & Terputus & Terputus \\
12 & 12 & Berhasil & Terputus & Terputus \\
13 & 13 & Berhasil & Terputus & Terputus \\
14 & 14 & Terputus & Terputus & Terputus \\
15 & 15 & Terputus & Terputus & Terputus \\
\hline
\end{tabular}

Hasil pengambilan sinyal suara paruparu dengan alat deteksi suara paru-paru berbasis android diambil pada posisi punggung bagian belakang. Suara diambil dari pasien bernama Bingar Sayekti P, berjenis kelamin laki-laki, usia 21 tahun, tinggi badan $169 \mathrm{~cm}$, berat badan $50 \mathrm{Kg}$. Sinyal suara paruparu ditampilkan pada osiloskop seperti pada Gambar 17. Gambar 18 adalah tampilan sinyal pada android sebagai bahan perbandingan.

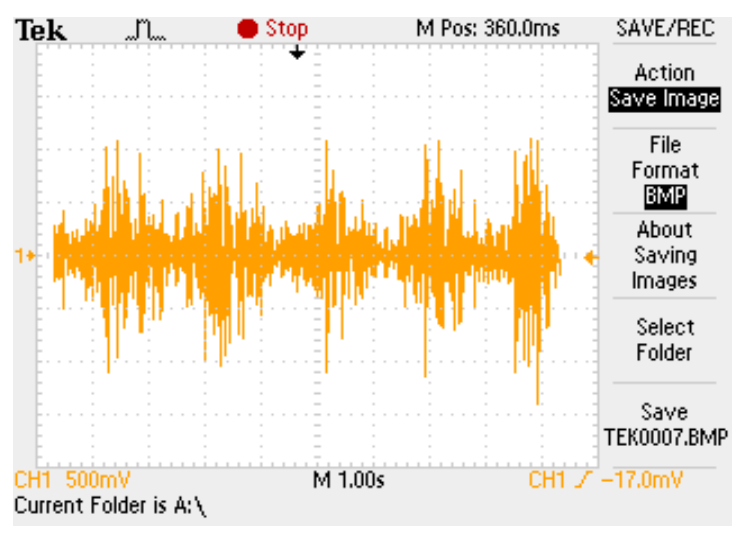

Gambar 17. Hasil Perekaman Sinyal Suara

Paru-Paru pada Osiloskop

Terlihat perbedaan tampilan sinyal suara paru-paru yang ditampilkan dari osiloskop dan grafik yang ditampilkan oleh android. Pada tampilan di osiloskop sinyal terlihat jelas, sinyal saat nafas (inspirasi) terlihat lebih tinggi dan saat buang nafas (ekspirasi) terlihat rendah, sedangkan sinyal suara paru-paru yang ditampilkan oleh android belum terlihat begitu jelas.

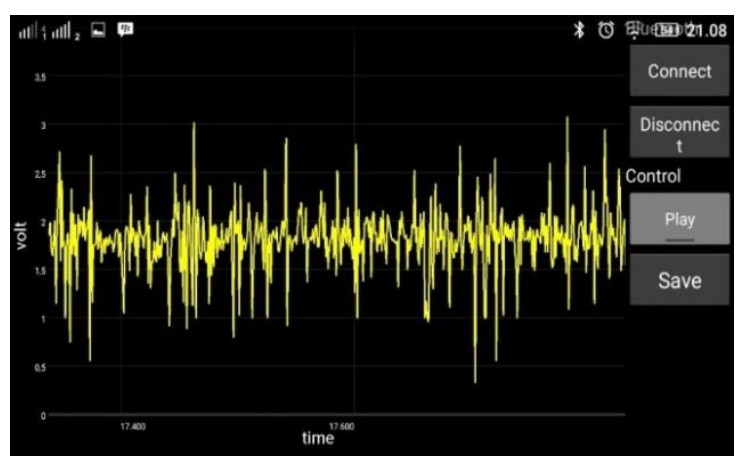

Gambar 18. Hasil Perekaman Sinyal Suara

Paru-Paru pada Android

\section{SIMPULAN}

Suara paru-paru berada pada frekuensi rendah sehingga perlu alat bantu untuk mendeteksi kelainan paru-paru pasien agar dapat dengan mudah untuk mendiagnosa penyakit paru-paru. Hasil penggabungan keseluruhan rangkaian sudah mampu memunculkan sinyal suara paru-paru pada osiloskop dan visualisasi di android, walaupun tampilan sinyal suara paru-paru pada android belum terlihat jelas dikarenakan mikrokontroler arduino uno tidak begitu cepat dalam pembacaan data dari rangkaian sehingga data yang dikirimkan melalui koneksi bluetooth tidak maksimal, jarak maksimal pengiriman data oleh Bluetooth tanpa halangan hanya sampai 13 meter, dengan halangan dinding beton 5 meter, dan dengan halangan dinding triplek 9 meter.

Dari hasil pengujian yang sudah dilakukan pada tiap-tiap rangkaian terdapat beberapa permasalahan dan kekurangan dalam perancangan, maka dari itu disarankan menggunakan mikrokontroler yang mempunyai kemampuan lebih tinggi seperti ARM AllwinnerA83T dengan CPU Octa-core Cortex-A7@1.6GHz dan RAM 2GB yang sudah memiliki koneksi wifi dan bluetooth 
sendiri sehingga dapat membaca dan mengirim data dengan cepat, Menambahkan range frekuensi menjadi $20-2500 \mathrm{~Hz}$ supaya dapat lebih banyak mendapat informasi dari sinyal suara paru-paru.

\section{DAFTAR PUSTAKA}

Achmad R, Suryani, Vera. 2007.Aplikasi Pengolahan Sinyal Digital pada Analisi dan Pengenalan Suara Jantung dan Paru untuk Diagnosis Penyakit Jantung dan Paru Secara Otomatis.STT Telkom. Bandung.

Budiasih, E., Rizal, A., \& Sabril, S. 2011. Pengembangan Stetoskop Elektronik dan Software Analisis Auskultasi. Proceding Seminar Nasional Sistem Informasi STIMIK Potensi Utama. Medan.

Departemen Kesehatan RI. 2000.Pedoman Nasional Penanggulangan Tuberkolosis. Catatan ke-5, Jakarta

Dian Artanto. 2012. Interaksi Arduino dan LabVIEW. ElexMedia Komputindo. Jakarta

Kemalasari, A. Wijayanto, \& P. Joko R.2011.Deteksi Kelainan Parenkim Paru Berdasarkan Power Spectra Density Suara Paru Dengan Metode Welch.The 13th Industrial Electronics Seminar 2011 (IES 2011). Politeknik Elektronika Negeri Surabaya. Surabaya
Matondang, S.C., Wahidiyat, I., \& Sastroasmono, S. 2003. Diagnosis Fisis Pada Anak. Sagung Seto: Jakarta

Oky Wahyu P, Hari Kurnia S, \& Sungkono. 2014. Sistem Kendali Gerak Robot Menggunakan PC berbasis Bluetooth.Jurnal Elektronika Otomasi Industri, Volume 1, Nomer 1. Politeknik Negeri Malang. Malang

Perhimpunan Dokter Paru Indonesia. 2010. Press Release: Year of the Lung 2010. Jakarta, 21Januari 2010

Ramadhan M. Z. 2012.Perancangan Sistem Instrumentasi untuk Identifikasi dan Analisis Suara Paru-Paru Menggunakan DSP TMS320C6416T. .Skripsi.Universitas Indonesia.Jakarta.

Suprayitno E.A., \& Arifin, A. 2012. Sistem Instrumentasi Sinyal Electrocardiography untuk Analisa Dinamika Jantung. Proceding Seminar Nasional Fisika Terapan II. Universitas Airlangga. Surabaya

WHO Team. 2008. World Health Statistics 2008. France: WHO

WHO Team. 2003. The Five Elements of DOTS. France: WHO

Yunisya Aulia P. 2014.Perancangan Aplikasi untuk Visualisasi Suara Paru-paru pada Manusia Berbasis Android. Skripsi. Medan 